ummary:

Control/Tracking Number: 19-A-679-BSR

Activity: Abstract

Current Date/Time: 10/29/2018 10:45:16 AM

\title{
THE BRITISH SOCIETY FOR RHEUMATOLOGY'S CHOOSING WISELY UK RECOMMENDATIONS
}

Author Block Charlotte A. Sharp ${ }^{1,2}$, Ian N. Bruce ${ }^{3,4}$, Benjamin M. Ellis ${ }^{5,6}$, Shuayb Elkhalifa ${ }^{7}$, James Galloway $^{8,9}$, Ben Mulhearn ${ }^{10}$, Jill Firth ${ }^{11}$, Joyce Fox ${ }^{12}$, Chetan Mukhtyar ${ }^{13}$, Daniel J. Murphy ${ }^{14,15}$, Anthony Rowbottom ${ }^{16}$, Neil Snowden ${ }^{11}$, Karen Staniland ${ }^{17,18}$, Elizabeth MacPhie ${ }^{19},{ }^{1}$ NIHR CLAHRC Greater Manchester, NIHR CLAHRC Greater Manchester, Greater Manchester, UNITED KINGDOM, ${ }^{2}$ Health Education England, North West, North West, UNITED KINGDOM, ${ }^{3}$ NIHR Manchester Biomedical Research Centre, Manchester University NHS Foundation Trust, Greater Manchester, UNITED KINGDOM, ${ }^{4}$ Arthritis Research UK Centre for Epidemiology, Faculty of Biology Medicine and Health, The University of Manchester, Manchester Academic Health Science Centre, Manchester, UNITED KINGDOM, ${ }^{5}$ Rheumatology, Hammersmith Hospital, Imperial College London NHS Trust, London, UNITED KINGDOM, ${ }^{6}$ Versus Arthritis, Arthritis Research UK, Chesterfield, UNITED

KINGDOM, ${ }^{7}$ Department of Immunology Salford Royal NHS Foundation Trust, Salford Care Organisation, Salford, UNITED KINGDOM, ${ }^{8}$ Department of Inflammation Biology, King's College London, London, UNITED KINGDOM, ${ }^{9}$ Rheumatology, King's College Hospital, London, UNITED KINGDOM, ${ }^{10}$ Manchester Collaborative Centre for Inflammation Research, Manchester Academic Health Sciences Centre, Manchester, UNITED KINGDOM, ${ }^{11}$ Pennine MSK Partnership, Oldham, Oldham, UNITED KINGDOM, ${ }^{12}$ Patient contributor, British Society for Rheumatology, Huddersfield, UNITED KINGDOM, ${ }^{13}$ Department of Rheumatology, Norfolk and Norwich University Hospital, Norfolk and Norwich, UNITED KINGDOM, ${ }^{14}$ Department of Rheumatology, Princess Elizabeth Orthopaedic Centre, Royal Devon \& Exeter Hospital, Devon \& Exeter, UNITED KINGDOM, ${ }^{15}$ Honiton Surgery, Honiton Surgery, Honiton, UNITED KINGDOM, ${ }^{16}$ Department of Immunology, Royal Preston Hospital, Lancashire Teaching Hospitals NHS Trust, Preston, UNITED KINGDOM, ${ }^{17}$ Patient contributor, British Society for Rheumatology, Greater Manchester, UNITED KINGDOM, ${ }^{18}$ School of Health \& Society, University of Salford, Salford, UNITED KINGDOM, ${ }^{19}$ Minerva Health Centre, Lancashire Care NHS Foundation Trust, Preston, UNITED KINGDOM.

\section{Abstract:}

Background: The Choosing Wisely UK campaign aims to promote shared decision making between patients and clinicians, helping people choose care that is supported by evidence, free from harm, truly necessary and consistent with their values. The Academy of Medical Royal Colleges (AoMRC), which coordinates the campaign, invited the BSR to submit 3-6 recommendations in 2018. The audience includes patients; rheumatologists and other physicians; GPs; nurses; allied health professionals.

Methods: The 14-member working group included two patient contributors, one consultant nurse, six consultant rheumatologists, one GP staff grade rheumatologist, two rheumatology trainees and two immunologists. The National Rheumatoid Arthritis Society and Versus Arthritis were represented. The working group was convened and recommendation development completed within 12 weeks. For the first part of the abbreviated Delphi-exercise, working group members submitted proposed recommendations with an accompanying evidence summary. These were collated and distributed (verbatim and anonymously) to the group to inform a ranking exercise. Members rated each topic from 5 (highest) to 1 (lowest) anonymously and left remaining topics unscored; topics with the highest scores were selected. A subgroup, including patient contributors, met to draft the recommendations. Evidence summaries were collated from information submitted in the initial proposals and from further contributions from working group members. External experts were consulted on each recommendation, following which consensus was sought from the working group to ratify the recommendations.

Results: Thirty-two proposals were received on 14 discrete clinical topics, from 10 working group members. Twelve members ranked topics. Six final recommendations were developed, all of which were endorsed by the BSR. The AoMRC accepted all six recommendations, proposing that ANA+ENA and $\mathrm{C} 3 / \mathrm{C} 4 / \mathrm{dsDNA}$ had clinician facing-recommendations only, due to their technical nature (table 1).Table 1 . BSR Choosing Wisely UK Recommendations 


\begin{tabular}{|c|c|c|}
\hline Topic & Our Patient Recommendations & Our Clinician Recommendations \\
\hline ANA \& ENAs & & $\begin{array}{l}\text { Testing ANA and ENAs should be } \\
\text { reserved for patients suspected to have a } \\
\text { diagnosis of a connective tissue disease, } \\
\text { e.g. lupus. Testing ANA and ENAs should } \\
\text { be avoided in the investigation of } \\
\text { widespread pain or fatigue alone. Repeat } \\
\text { testing is not normally indicated unless the } \\
\text { clinical picture changes significantly. }\end{array}$ \\
\hline $\begin{array}{l}\text { Rheumatoid } \\
\text { Arthritis }\end{array}$ & $\begin{array}{l}\text { If a doctor suspects that you have } \\
\text { rheumatoid arthritis, it is recommended } \\
\text { that you are referred to rheumatology } \\
\text { without delay, even before any tests are } \\
\text { done. There is no single blood test which } \\
\text { can determine whether someone does or } \\
\text { does not have rheumatoid arthritis. }\end{array}$ & $\begin{array}{l}\text { Patients with suspected inflammatory } \\
\text { arthritis should be referred to } \\
\text { Rheumatology without delay. Rheumatoid } \\
\text { factor and CCP/ACPA are important, but } \\
\text { should be avoided as screening tests. A } \\
\text { negative result does not exclude } \\
\text { rheumatoid arthritis, nor does a positive } \\
\text { result equate to a diagnosis of rheumatoid } \\
\text { arthritis. Repeat testing is not normally } \\
\text { indicated. }\end{array}$ \\
\hline Vitamin D & $\begin{array}{l}\text { It is important for everyone to take } \\
\text { Vitamin D supplements during winter. If } \\
\text { you have restricted access to sunlight (e.g. } \\
\text { if you live in a care home or cover your } \\
\text { skin), or have dark skin, it is recommended } \\
\text { that you take a supplement all year round. } \\
\text { Vitamin D testing is unlikely to be useful } \\
\text { or necessary in most people and future } \\
\text { testing is not normally needed for those } \\
\text { taking supplements. }\end{array}$ & $\begin{array}{l}\text { Everyone should consider Vitamin D } \\
\text { supplementation during winter. People } \\
\text { who have restricted access to sunlight (e.g. } \\
\text { those living in institutions or who cover } \\
\text { their skin), or have dark skin, should } \\
\text { consider supplementation all year round. } \\
\text { Vitamin D testing should be reserved for } \\
\text { people at high risk from deficiency and } \\
\text { avoided as part of routine investigation of } \\
\text { widespread pain alone. Repeat testing is } \\
\text { not normally indicated in those taking } \\
\text { supplements. }\end{array}$ \\
\hline Osteoporosis & $\begin{array}{l}\text { Bisphosphonates are drugs that help } \\
\text { reduce fracture risk due to bone thinning } \\
\text { (osteoporosis). People who take } \\
\text { bisphosphonate treatment should discuss } \\
\text { this with their healthcare professional } \\
\text { every 3-5 years because it may be } \\
\text { advisable for some to have a break in } \\
\text { treatment. }\end{array}$ & $\begin{array}{l}\text { Bisphosphonate therapy should be } \\
\text { reviewed with every patient after } 3-5 \\
\text { years, and a treatment holiday considered. } \\
\text { This should follow a shared-decision } \\
\text { making conversation which includes the } \\
\text { risks and benefits of continued treatment. }\end{array}$ \\
\hline $\begin{array}{l}\text { Steroid } \\
\text { injections }\end{array}$ & $\begin{array}{l}\text { It is recommended that you have a } \\
\text { conversation with your healthcare } \\
\text { professional before accepting steroid } \\
\text { injections for non-inflammatory } \\
\text { musculoskeletal conditions. So that you } \\
\text { can make an informed decision, this } \\
\text { discussion should include the risks, } \\
\text { benefits, and alternatives such as exercise } \\
\text { and physical therapy. Although some } \\
\text { people may experience short term benefit, } \\
\text { there are potential long-term risks with } \\
\text { repeated injections. }\end{array}$ & $\begin{array}{l}\text { The use of intra-articular and soft-tissue } \\
\text { steroid injections for non-inflammatory } \\
\text { musculoskeletal conditions should be } \\
\text { preceded by consideration of non-invasive } \\
\text { alternatives such as exercise and physical } \\
\text { therapy. Consent to any invasive procedure } \\
\text { such as this must arise from a shared- } \\
\text { decision making conversation with every } \\
\text { patient, which includes assessment of the } \\
\text { risks and benefits. }\end{array}$ \\
\hline $\begin{array}{l}\text { C3, C4 \& } \\
\text { dsDNA in }\end{array}$ & & $\begin{array}{l}\text { C3, C4 and dsDNA are important tests to } \\
\text { help in the diagnosis and assessment of } \\
\text { disease activity in lupus. They should be }\end{array}$ \\
\hline
\end{tabular}


Conclusion: Six recommendations were developed by a multidisciplinary team including people with arthritis. Because of the robust development process, we believe these recommendations are acceptable, meaningful and practical. Their application will lead to more personalised care, increased patient and clinician satisfaction, and better use of limited resources. We encourage all BSR members to engage with and champion these recommendations to inform shared decision-making conversations with patients.

Category (Complete): Health service research

Keyword (Complete): Choosing Wisely ; Shared decision making ; Person centred care

Funding and Disclosures (Complete):

Click here to affirm the above Licence to Publish: True

Funding: No

Additional (Complete):

I agree: True

Please select : Submitted previously

British Society for Rheumatology: Yes

British Society for Immunology: No

Prizes and Awards (Complete):

Apply for Health Professionals in rheumatology clinical prize: Apply I confirm that I am a member of the British Society for Rheumatology : True

Apply for Young Investigator Award: Apply

Apply for Student/ Recently Qualified Health Professional Nurse Bursary: Decline Apply for BSR/ASME educational research prize : Decline 